\title{
Diferencias culturales en el mundo global: cuestiones irresueltas para los pueblos indígenas de América Latina
}

\author{
Cultural differences in the global world: unresolved \\ issues for indigenous people from Latin America
}

María Isabel González Terreros ${ }^{1}$

Resumen

El mundo, y en particular América Latina, vive procesos de tensión y disputa cultural, producto del conflicto que se presenta ante la globalización, la cual plantea perspectivas y políticas universales, $y$ las manifestaciones de comunidades indígenas que reclaman el reconocimiento de la diferencia y el derecho a la identidad. En tal sentido, este artículo pretende analizar diferentes tensiones en las cuales se encuentran los pueblos indígenas en el contexto de la globalización. Tensiones que tienen que ver con las políticas internacionales y nacionales que cobijan a los pueblos indígenas, las manifestaciones y los reclamos de los movimientos indígenas por el reconocimiento de su identidad cultural y la tensión en que se encuentra la identidad colectiva en medio del mundo globalizado.

\section{Palabras clave}

Pueblos indígenas, identidad, diferencia cultural, globalización, multiculturalidad.

\section{Abstract}

The world, particularly Latin America, is living several cultural processes of tension and dispute, which are the result of the conflict between globalization (that implies universal perspectives and policies), and the claims of indigenous communities which seek to achieve recognition of their differences and the right to their own identities. In this sense, the present paper aims to analyze the different tensions in which indigenous people are immersed, in the context of globalization. These tensions are related, first, to international and national policies that encompass indigenous people; secondly, to manifestations and demands of indigenous movements for the recognition of their cultural identity; and finally, to the tension itself in which collective identity is involved, in the context of a globalized world.

\section{Keywords}

Indigenous people, identity, cultural difference, globalization, multiculturalism.

Artículo recibido el 24 de julio de 2009 y aprobado el 16 de octubre de 2009.

1 Docente de la Universidad Pedagógica Nacional. Programa Educación Infantil. Licenciada en Ciencias Sociales con Maestría en Educación con énfasis en enseñanza de la historia de la Universidad Pedagógica Nacional. Postulante al Doctorado de Estudios Latinoamericanos en la Universidad Nacional Autónoma de México, UNAM. Correo electrónico: isabelgonzalezt@yahoo.es 
América Latina es un continente que se caracteriza por su diversidad cultural: pueblos indígenas, afroamericanos, mestizos, blancos y variedad de poblaciones llegadas de otras latitudes, integradas en el continente y oriundas de éste conforman la región desde hace más de cinco siglos; pero también diversidades sexuales, religiosas, étnicas, de clase, entre muchas, forman parte del entramado cultural llamado América Latina.

Esta característica, que enriquece al continente, se ha hecho más visible en las últimas décadas, producto tanto de las diferentes manifestaciones realizadas por las comunidades indígenas, afroamericanas, entre otras, que han mostrado su inconformidad por la falta de reconocimiento cultural y social de los estados de los cuales forman parte, como producto de la movilidad social y cultural que el mundo vive no sólo en términos físicos sino de la rapidez en la comunicación que ha facilitado el acercamiento entre las culturas y las que no habían establecido contacto, se encontraran y, en muchos casos, entraran en conflicto. Esta, que es una de las características de nuestro continente, también es uno de los rasgos actuales de la sociedad globalizada, vivimos en medio de una multiplicidad de culturas e identidades que se reconocen, valoran e intercambian; ya no vivimos en aldeas separadas unas de otras, sino que precisamente el mundo es global y todos formamos parte de él, de sus flujos, redes, intercambios, etc.

Es decir, el contexto actual de globalización, como de movilización de las organizaciones sociales, hizo más visible la diversidad cultural que ha integrado el continente. Sin embargo, esta diversidad cultural también se ha evidenciado por medio de las constantes tensiones entre las poblaciones que lo conforman; las relaciones de poder que se establecen entre diferentes grupos sociales y culturales; las luchas por afirmarse en el territorio; las mezclas culturales; los desencuentros; los distanciamientos entre diferentes culturas; las formas de representarse los unos a los otros; las imposiciones, entre otras situaciones que constituyen y han configurado la historia del continente americano.

Desde este contexto, se podría pensar que hablar de multiculturalismo cobra sentido, la sociedad es un mundo plural y diverso en el que se reconfiguran las identidades, se viven identidades cambiantes que se tocan con otras y se recrean. Sin embargo, esta idea multiculturalista, entendida como la coexistencia de diferentes culturas en un espacio determinado y en la cual todos pueden vivir en relaciones de tolerancia, desconoce las opciones de múltiples comunidades indígenas, que sienten que su identidad se encuentra en peligro al ser ellos quienes deben recrear y reconfigurar sus identidades desde la propuesta cultural de sus estados y del mundo global en general.

La tensión globalidad y comunidad es una constante en la que se encuentra el mundo y América Latina en particular, pues, por un lado, existen comunidades que reclaman su derecho a la diferencia y, por otro, un mundo global que intercambia significados y de alguna forma homogeneiza las relaciones. Así, los reclamos por la cultura, la identidad y la autonomía no se hacen esperar, las organizaciones se movilizan; los conflictos se agudizan; la legislación se queda corta y la discriminación continúa.

La diferencia cultural, la globalización, la identidad, la movilidad, los reclamos de los pueblos étnicos han dejado ver que el mundo se encuentra en un momento de tensión cultural. Situación que ha llevado a hacer interrogantes, afirmaciones y cuestionamientos como las que hace Rodolfo Stavenhagen (2000, p. 325): ¿es posible la nación multicultural?; Gilberto Giménez (2000, p. 49) afirma que la mayoría de estados son plurinacionales, multiétnicos y plurilingüísticos y León Olivé (2004, p. 139) se cuestiona lo siguiente: ¿ es posible un mundo globalizado y plural proponer un conjunto de normas y valores que podrían ser compartidos por seres humanos con moralidades diferentes? Cuestiones que dejan en el ambiente un dilema: ¿cómo vivir en un mundo global sin perder el derecho a ser diferentes? En la actualidad, existen preguntas difíciles de contestar, respuestas que tal vez son criticables, afirmaciones sesgadas. Pero, en general, todo ello refleja las preocupaciones por entender el mundo actual; la urgencia por pensar la movilidad que éste vive y la necesidad de tener marcos referenciales de cómo abordarlo.

Este artículo, precisamente, trata de abordar estas tensiones, que resultan ser cuestiones irresueltas, pero no con el ánimo de dar las respuestas, sino, por el contrario, de entender de manera contextual los cuestionamientos en los que se encuentra el debate de los pueblos indígenas en medio del mundo global. Para ello, se tratan de abordar diferentes tensiones: la identidad y la globalización; las políticas internacionales para poblaciones indígenas y los reclamos de las organizaciones indígenas en el contexto global. 


\section{La identidad y la globalización}

Las culturas tienen sus propias formas de ver el mundo, de estar en un espacio, de representarse, de priorizar sus intereses, reclamos, etc. Estos componentes, que son constitutivos e importantes de las culturas, son al mismo tiempo componentes de la identidad. Pero ¿cuál es el límite entre cultura e identidad?, esta es una cuestión compleja, pero a la vez fundamental para entender las relaciones sociales del mundo, de sus culturas y de sus sujetos.

La relación entre cultura e identidad es muy estrecha y, más allá de entrar en la discusión sobre qué es la cultura, nos interesa abordarla desde su nexo con la identidad. Para Gilberto Giménez, "el concepto de identidad es inseparable de la idea de cultura, debido a que las identidades sólo pueden formarse a partir de las diferentes culturas y subculturas a las que se pertenece o en las que se participa" (2007, p. 54). La identidad es ante todo una construcción social basada en el vínculo que los sujetos establecen con su cultura y con culturas disímiles. En tal sentido, se pueden establecer dos proceso de relación entre la identidad y la cultura: uno de ellos encuentra la cultura como un espacio que posibilita a los sujetos relaciones de aprendizaje, de intercambio, de pertenencia, de identificación como fuentes bajo las cuales se construye la identidad del sujeto en su cultura; y en el otro se encuentra la cultura como la posibilidad de diferenciación con otras, es decir, posibilita la distinción del sujeto cultural frente al otro que es distinto. En tal sentido, la identidad no se puede entender cerrada a las influencias externas e internas, ya que la identidad se construye a partir del contacto y la cercanía que la cultura y sus sujetos establecen entre ellos y con la sociedad.

La identidad constituye un vínculo, pero a la vez es una diferenciación que los sujetos y sus culturas establecen con otros grupos y con la sociedad en general. Vínculo en la medida en que los sujetos y los colectivos son seres sociales portadores de identidad que, al encontrarse en relación con los otros, con la sociedad, intercambian significados; constituye una diferenciación porque este intercambio genera -en algunos casos- tensiones, disputas y pérdida o transformación de referentes para los sujetos que "intercambian" y para la cultura de la cual forma parte.

Al hablar de identidad, nos encontramos ante la diferenciación de unas culturas con otras, que distinguen y demarcan, en cierta forma, su frontera de diferenciación. Pero las identidades no son esencias que no se tocan y conviven aisladas unas de otras, sino que existe una especie de flexibilidad y mestizaje producto de la relación cultural con otras poblaciones; en el caso de América Latina, con poblaciones europeas, africanas y americanas, por ello no podemos decir que existen "purezas culturales", sino, por el contrario, una hibridación cultural producto de la historia relacional de América Latina con el mundo. Esta situación es innegable, pero también es innegable que la diversidad está integrada por relaciones de poder, jerarquía, discriminación, desconocimiento, imposición, etc. Esto se evidencia en que en el proceso de identificación, al entrar en contacto unas culturas con otras, algunas ceden más, toman más, son más permeables o menos hegemónicas, algunas se diluyen, otras desaparecen, algunas se camuflan, etc.

En tal sentido, si por identidad entendemos:

El conjunto de repertorios cultuales interiorizados (representaciones, valores y símbolos) por medio de los cuales los actores sociales (individuales y colectivos) demarcan sus fronteras y se distinguen de los demás en una situación determinada, todo ello en un espacio históricamente específico y socialmente estructurado (Giménez, 2000, p. 54).

La identidad establece distinciones y diferenciaciones entre grupos. Estas diferenciaciones pueden ser referentes (atributos, características) fundamentales de los grupos de pertenencia de los sujetos, referentes como la religión, que distingue a los musulmanes de los cristianos, o la etnia, que distingue a los indígenas de los mestizos. Cuando se trata de diferencias, que son fundamentales para la identidad de los grupos, éstas pueden llevar a tensiones y conflictos sociales que a su vez puede generar límites más demarcados entre los grupos e intercambio que van a transformar la identidad y en algunos casos perder referentes esenciales o no de la identidad social de ciertas culturas².

2 Gilberto Giménez nos llama la atención para no hacer uso descuidado del concepto de identidad social porque "es apto para integrar mitos políticos con fuertes resonancias pasionales como el nacionalismo clásico, los etno nacionalismos europeos y el racismo disfrazado bajo la reivindicación del derecho a la diferencia" (2000, p. 54). 
Ahora bien, es común que tienda a pensarse la identidad colectiva como una entidad homogénea y totalizante. Sin embargo, para cada cultura los referentes que las definen y las constituyen van a tener una importancia y una raigambre distintas, ya que en la configuración de las identidades los sujetos se relacionan con otros y de allí, de forma selectiva y distintiva, toman rasgos y referentes que consideran (consciente o inconscientemente) pueden fortalecer su proceso de diferenciación, identificación en el seno de una sociedad. Para cada caso, los referentes van a tener un valor diferenciado, algunas culturas y comunidades en su proceso de identidad dan mayor valor a la etnia, el género, la edad, la clase, la religión, la política, entre muchas otras, $\mathrm{o}$ a combinaciones de varias de ellas. Es necesario aclarar aquí que la identidad no está constituida por elementos como si se tratara de objetos disociados que se tienen o se dejan, se separan o integran; se trata de referentes que tienen un valor para la comunidad y que le permiten diferenciarse de otras comunidades y culturas, pero a la vez reconocer a otras e intercambiar con ellas. Los referentes constituyen a la identidad, es decir, no por el hecho que la cultura dé mayor prioridad a unos referentes que otros éstos se encuentran disociados, por el contrario, no se separan, se encuentran en relación, e incluso en disputa, porque están abiertos a las influencias de las redes cercanas y la sociedad en general.

Así, las fuentes sobre las cuales se define y constituye la identidad colectiva de comunidades van a ser diferentes, en el sentido que mientras para las comunidades indígenas la tierra y el territorio son fundamentales para fortalecer su identidad, para otras culturas la tierra y el territorio los constituye, pero su fundamento se puede encontrar en el género, en lo religioso, en lo étnico. Incluso, va a ser diferente la forma en que cada comunidad indígena genera identidad con la tierra y el territorio, las representaciones que se han creado de ésta, la manera en que lo reclaman, su cosmovisión, etc.

Por ello, la identidad como una cuestión inmersa en parámetros globales es un asunto complejo, e incluso problemático, ya que se trata de dar cabida a múltiples formas de identidad bajo -se quiera o no reconocer- unos parámetros universalizantes. El territorio como fuente fundamental de la identidad de algunas comunidades indígenas, riñe con la idea capitalista de la propiedad privada, por ejemplo, de comercio de plantas medicinales, de extracción de hidrocarburos. El comercio y la venta de la tierra y de sus "productos" altera los ecosistemas donde habitan comunidades que han creado con el territorio una identificación fundamental para su identidad. Este es el caso de las comunidades de la amazonía ecuatoriana ${ }^{3}$ que han sido testigos y afectados directos de la mercantilización, explotación y comercialización de los recursos naturales de la región desde finales del siglo XIX. Dos sectores de mercantilización y explotación fueron los más fuertes: la explotación de caucho y petróleo que trajo consigo la colonización del territorio, la cual estuvo marcada por el arribo de diferentes sectores: caucheros, peroleros, militares, religiosos, comerciales, migrantes. Este proceso de explotación y colonización de la selva trae consigo referentes disímiles y antagónicos a las comunidades ancestrales, y como no todas las culturas tienen el mismo poder en el proceso de "intercambio" cultural, se ha generado una pérdida de referentes identitarios fundamentales para las comunidades shuar, al alterar los ecosistemas que habitan $y$, por ende, la vida de las comunidades indígenas. De manera similar, existen ejemplos en varios países de América (Colombia, Bolivia, México, Panamá, Perú).

3 A finales del siglo XIX e inicios del XX, en la Amazonía se instaló la explotación del caucho como materia prima para la naciente industria automotriz. La llegada de nuevos colonizadores: comerciantes, trabajadores, hacendados junto con la infraestructura que esta industria requirió para la extracción, alteró el ecosistema de la región donde han habitado algunas comunidades indígenas como la Shuar quienes hicieron parte de este sistema de explotación al ser contratados como trabajadores de las caucheras. En este proceso de mercantilización de materias primas también se encuentra la explotación del petróleo desde inicios del siglo XX, específicamente desde 1921 cuando el gobierno ecuatoriano concede a Leonard Corporation una gran extensión de tierra en la Amazonía para la búsqueda de petróleo a cambio de la construcción de un camino que conectara a esta región con la sierra. Posteriormente, en 1964 se entrega gran cantidad de territorio amazónico a la multinacional Texaco Gulf para la explotación de petróleo. La colonización de la región, también estuvo a cargo de otros sectores: los militares ecuatorianos y misiones religiosas. Los litigios en la frontera entre Ecuador y Perú ha sido uno de las constantes situaciones por la que se han enfrentado estos dos países, este hecho unido con la necesidad de establecimiento del Estado en el territorio amazónico, llevó a que el gobierno de Eloy Alfaro (1901-1905) enviara tropas para militarizar la frontera, a la vez que realizaba una legalización de tierras. Por otra parte, a la amazonía arribaron diferentes misiones religiosas, algunas ya estaban asentadas en la zona y unas nuevas llegaban como es el caso del Instituto Lingüístico de Verano que fue una misión evangélica norteamericana que tenía como objetivo la enseñanza del bilingüismo en América Latina. 
Hablar de identidad, haciendo referencia a comunidades especificas en plural, es un campo muy espinoso porque se tiende a hacer generalizaciones, por ejemplo, al hablar de comunidades indígenas se pensaría que todas enfatizan en los mismos referentes identitarios que se han mencionado o que todos sus sujetos poseen la misma identidad. Sin embargo, cada comunidad constituye una identidad diferente y una relación con la sociedad y los referentes que la componen que la hacen única en el mundo; incluso en la misma comunidad existen perspectivas diversas y sentidos de pertenencia disímiles que les dan identidad a los sujetos que la conforman. Al respecto, Gilberto Giménez plantea dos tipos de atributos a los que el sujeto apela para demarcar la distinción entre demarcación y autonomía con respecto a los otros:

1) atributos de pertenencia social que implican la diferenciación del individuo con diferentes categorías, grupos y colectivos sociales; 2) atributos particulares que determinan la unicidad idiosincrática del sujeto en cuestión. Por lo tanto, la identidad contiene elementos de lo socialmente compartido resultante de la pertenencia a grupos y otros colectivos, y de lo individualmente único. Los elementos compartidos destacan las similaridades, mientras que los individuales enfatizan en la diferencia (Giménez, 2007, p. 62).

La identidad, en su proceso de configuración tanto personal como colectiva, obligatoriamente entra en relación con otras formas de ver el mundo y conlleva intercambiar referentes individuales y colectivos. En este proceso se puede presentar una legitimación cultural y valoración de ciertas características de las culturas que se intercambian, como también un desconocimiento o rechazo de algunos referentes fundamentales para las culturas. Este proceso no se puede ver desde los extremos: repulsión o asimilación, pues "una de las características de la identidad es su plasticidad, la capacidad de variación, adaptación, modulación e incluso manipulación" (Giménez, 2000, p. 57), lo que lleva a que la identidad cultural se vaya amoldando, acomodando, diferenciando, redefiniendo desde otras formas de representar el mundo. Sin embargo, en la medida en que al demarcar las fronteras de una identidad cultural se ponen en juego relaciones de poder de los grupos culturales y de sus sujetos, las culturas entran en choque y se puede generar procesos de asimilación, desconocimiento, devaluación o simplemente generar un proceso de intercambio.

Es precisamente en medio de estas tensiones acrecentadas en el mundo global donde surge el concepto de multiculturalidad, entendida como la posibilidad que tienen diferentes culturas de convivir en un mismo espacio. Pero este concepto resulta ser un discurso de legitimización de unas identidades y unas culturas por encima de las otras, ya que ese intercambio representa también una forma de ver el mundo, es decir, la idea que todos podemos vivir con nuestras diferencias en un mundo global. Sin embargo, son más valoradas unas diferencias que otras y las menos valoradas deben acomodarse al patrón impuesto que se presenta como tolerante de la diferencia.

La idea de intercambio cultural de manera equitativa entra en choque con culturas que tienen una identidad con arraigo histórico, sin querer decir con ello que no son flexibles, pero que en sus bases tiene una identidad fuerte que se ha construido sobre todo a partir del antagonismo con el universal homogeneizante; por ejemplo, la identidad indígena en contraposición con la cultura occidental. La identidad, como construcción social, "se realiza en el interior de marcos sociales que determinan la posición de los actores y, por lo mismo, orientan sus representaciones y acciones" (Giménez, 2000), marcos que no son plurales ni horizontales, y bajo los cuales los reclamos la legitimidad cultural y la identidad de las comunidades indígenas se ve menospreciada desde los parámetros multiculturalistas.

Las posibilidades de una vida conforme las identidades culturales, sociales, económicas y políticas de las comunidades indígenas en el mundo global, son cada vez menos posibles, y el multiculturalismo se queda corto para abordar estas diferencias antagónicas. En tal sentido, no todas las relaciones sociales son positivas, como se muestra desde la propuesta de la multiculturalidad, en el sentido que nos enriquecemos culturalmente de este intercambio, sino que al mismo tiempo están aflorando diversidad de desconocimientos culturales y étnicos, producto de este cruzamiento cultural y territorial. Desconocimientos generados por la discriminación, el poder de las culturas hegemónicas, que en algunos casos llevan a guerras por territorio, por la religión, por la legislación, entre otros. 
Esto deja ver que el mundo se encuentra en dilema y en tensión, pues por un lado asistimos a un mundo globalizado conformado por diferentes culturas que entran en contacto, se conocen, forman redes, se hacen visibles, se intercambian, se reafirmar. Pero, por el otro, el mundo está conformado por una serie de culturas, identidades, minorías 4 que reclaman su derecho a la diferencia, a la autonomía, a ser reconocidas desde características antagónicas con el patrón universalizante, que bajo la idea de multiculturalidad se impone al mundo. ¿Cómo abordar esta diferencia cultural en un mundo con políticas globales?

\section{Los pueblos indígenas en la políticas internacionales}

La globalización y el derecho a las minorías parecen ser dos cuestiones incompatibles e inconmensurables. ¿Cómo plantear políticas para poblaciones que se salen del patrón cultural para el cual están diseñadas las políticas en el mundo global? Estas son cuestiones mayúsculas que tienen en tensión a organismos internacionales como la ONU, ya que las demandas de las comunidades indígenas son incompatibles con los derechos legislados desde la política liberal, que es la que sigue primando alrededor del mundo, específicamente en América Latina.

La complejidad cultural del mundo y sus reclamos va tan rápido que las legislaciones al respecto se quedan caducas frente al contexto o, simplemente, quienes legislan no se preocupan por atender las demandas de las poblaciones, ya que ellas requerirían otro tipo de política legislativa. Varias han sido las voces que se han pronunciado por la necesaria definición de políticas que cobijen las demandas de los grupos sociales que reclaman el derecho a su identidad y la autonomía. Desde esta perspectiva, León Olivé (2004) plantea que es indispensable pensar en normas, valores e instituciones que faciliten la resolución pacífica de los conflictos en los pueblos de América Latina, el desafío es resolver la tensión entre el movimiento

4 El concepto de minoría presenta dificultades para su uso, en la medida en que se ha utilizado para connotar poblaciones indígenas que en muchos casos son mayoría numérica en sus países o como concepto despectivo describiendo la poca importancia que puede tener un grupo en una sociedad. Sin embargo, en este caso se usa para nombrar a los grupos poblacionales que no hacen parte de las decisiones gubernamentales de sus países y son marginados. a la comunidad mundial homogénea y la voluntad creciente de los pueblos de mantener su identidad.

A pesar de las manifestaciones por el reconocimiento de la identidad colectiva, en la actualidad se impone la mirada universalizante (aunque en algunos países se hagan pequeñas variantes); las propuestas globales son las que priman. Esto se hace evidente porque en las políticas culturales quienes legislan, en primera medida, son organis-mos internacionales como la ONU, La Unesco y la OIT, las cuales han promulgado políticas universales que permean el mundo y a las culturas locales en particular. La Organización de la Naciones Unidas -ONU- realiza políticas que se viabilizan por medio de la promulgación de los derechos económicos, sociales y culturales o los derechos de los pueblos; la Organización de las Naciones Unidas para la Educación, la Ciencia y la Cultura-UNESCO- debate un convenio internacional sobre la diversidad cultural y el derecho a la identidad; la Organización Internacional del Trabajo -OIT- (agencia especializada de la ONU) planteó en el Convenio 169 la necesidad del "mejoramiento del nivel de vida y del trabajo de las poblaciones indígenas".

La ONU adoptó en 1966 los derechos económicos, sociales y culturales que forman parte de los derechos humanos:

Dos principios fundamentales forman la base del edificio de los derechos humanos en la actualidad: el principio de la igualdad de todos los seres humanos ante la ley y correlativo a éste, el de la no discriminación por motivo de género, raza, color o pertenencia étnica (Stavenhagen, 2000, p. 327).

Aquí se presenta una de las tensiones porque se habla del derecho a la igualdad, pero a la vez el derecho a la diferencia, cuando se plantea la no discriminación por raza, color y etnia. En tal sentido opera la máxima "Somos iguales pero diferentes", que funge como una narrativa universal plasmada en discursos de los políticos y las políticas culturales de varios países donde se crean legislaciones que hablan del derecho a la igualdad y a la diferencia, ¿cuál es el problema de reconocer ambos derechos?

En las legislaciones nacionales se reconoce el derecho a la educación como derecho a la igualdad, pero a la vez el derecho a que las comunidades 
indígenas intervengan en las propuestas educativas de sus comunidades como derecho a la diferencia. Sin embargo, la escuela debe seguir siendo la misma, los grados siguen siendo los mismos, las materias básicas se deben seguir manteniendo. De este modo, el derecho a la igualdad es continuar con la propuesta educativa moderna, a la cual se le "cuelgan" algunos aspectos de las culturas indígenas, y el derecho a la diferencia es integrarse al proceso de la educación que ha sido planteada por los estados bajo el parámetro de mestizaje.

La máxima "Todos somos iguales pero diferentes" también se hace evidente en los derechos ciudadanos. Ésta fue una política implementada por los estados modernos para configurar el nacionalismo de las poblaciones que se encontraban en las fronteras del Estado. Estos derechos tuvieron su sustento en la idea según la cual todos somos ciudadanos iguales ante la ley, que contribuyó a fortalecer la homogenización cultural de los países en América Latina.

Paradójicamente, los derechos ciudadanos basados en el liberalismo individual continúan en la actualidad, obviamente reconfigurando la idea de homogenización hacia una perspectiva que reconozca la diversidad del mundo. El liberalismo es el sustento de las políticas internacionales y nacionales, el cual promulga el individualismo, en la medida en que los derechos humanos están basados en el derecho a la individualidad (derecho a la diferencia) y la ciudadanía (todos somos iguales ante el Estado). Al decir de Stavenhagen, el individualismo liberal sigue siendo la política del capitalismo a manera de sistema cultural y social que desconoce otras formas culturales como lo proponen las comunidades indígenas que no sienten el capitalismo a modo de un sistema que los integre.

Así, las políticas liberales integran la diversidad cultural, pero no integran la diferencia producto de las identidades culturales antagónicas al modelo universalizante. Estas políticas se promulgan sin tener en cuenta los reclamos culturales y sociales de las comunidades indígenas, o que si se tienen en cuenta éstos no respetan en su totalidad el derecho a la diferencia y la identidad de los pueblos ${ }^{5}$.

5 Esto sucede incluso en países que se consideran de avanzada en las políticas indígenas. Es el caso del Ecuador y Bolivia, en los dos países se reconoce el derecho a la diferencia, incluso en el caso del Ecuador, la constitución promulgada en 2008 plantea el reconocimiento de la nacionalidades indígenas, con lo cual se podría
Es decir, se reconoce la diversidad cultural, manteniéndose las ideas universalistas bajo parámetros hegemónicos.

La diferencia cultural se sigue abordando desde la ideología liberal, que ha tomado el discurso de la multiculturalidad como perspectiva que le permite fortalecer la mirada del individuo, pero esta vez reconociendo discursivamente que la sociedad es diversa, y que esta diversidad hace al mundo más humano y enriquecido. El multiculturalismo es una política basada en un universal moderno que reconoce derechos individuales, base de la política liberal que ha imperado en los estados latinoamericanos, por ello, la mayoría de políticas están centradas precisamente en la multiculturalidad y no en derechos colectivos, que son los que reclaman las comunidades.

Plantear los derechos colectivos como el derecho a la autodeterminación de los pueblos es visto como un gran problema para la política liberal, por considerarse que este derecho pondría en peligro el Estado nacional y se acrecentaría la posibilidad de conflictos étnicos en la región. Al respecto, nos comenta Stavenhagen que:

Hace algunos meses tuvo lugar, en algún lugar de América Latina, un seminario organizado por la CIA, para explorar los distintos escenarios a futuro de los países de la región. Uno de los temas que más ha preocupado a los comentaristas es precisamente el de la emergencia política de los movimientos indígenas, considerada por algunos como un peligro para la estabilidad de de la región. El caso más citado por ahora es el de Bolivia en donde diversas organizaciones indígenas decidieron ocupar los espacios públicos para cambios en la política nacional (Stavenhagen, 2007, p. 393).

El reconocimiento de la autodeterminación de las comunidades indígenas ha sido una de las mayores preocupaciones de los organismos internacionales como la ONU. Por ello, la "Declaración

\footnotetext{
pensar que se reconoce el derecho a la autodeterminación, sin embargo, la disputa entre el Estado y las comunidades se centra en que no se permite a las comunidades el derecho de decidir por su territorio, incluso ni la posibilidad a tener veto sobre lo que el Estado proponga, haga o no en sus tierras. En tal sentido, el Estado tienen la libre facultad de decidir sobre el territorio que habitan los indígenas.
} 
de las Naciones Unidas sobre los derechos de los pueblos indígenas" realizada en el 2007, se da después de más de veinte años de negociaciones en el seno de dicha institución. Las discusiones para la aprobación de la Declaración se centraron en torno a conceptos como pueblo y autonomía, ya que éstos, según la ONU, podrían llevar a la fragmentación de los estados. Para Bengoa (2000), el concepto de pueblo tiene una carga jurídica muy fuerte en el derecho internacional desde el reconocimiento de la Declaración Universal de los Pueblos, en 1976, en la cual se le concede al pueblo derecho a territorio, límites y soberanía. Estos son los derechos desde los cuales se rigen los actuales estados en el mundo, y si se les concede a los indígenas el derecho a ser pueblo, la ONU supone que las comunidades indígenas podrían solicitar la separación de sus respectivos estados.

Por su parte, varios movimientos indígenas, como el Ejercito Zapatista de Liberación Nacional -EZLN- de México, la Confederación de Nacionalidades Indígenas del Ecuador -Conaie- y el Movimiento al Socialismo -MAS- en Bolivia, han manifestado abiertamente que su movimiento no es separatista, ni le interesa la secesión del Estado. Pese a ello, los estados participes de la Asamblea General de la ONU tuvieron múltiples discusiones en torno a la aprobación de la Declaración de los derechos de los pueblos indígenas. Finalmente, se reconoce el derecho a la determinación y autonomía, pero bajo unos límites que establece la organización.

En términos jurídicos, según Bengoa (2000), el carácter de pueblo conlleva al derecho de autodeterminación. Por ello, al firmar la Declaración de los Derechos de los Pueblos, la ONU dejó claro que "el derecho a la autodeterminación está relacionado con el derecho de los pueblos indígenas al autogobierno y a la autonomía en lo que se refiere a sus asuntos internos y locales", es decir, no se posee injerencia nacional, aunque las comunidades indígenas pueden participar de las políticas propias del Estado del cual forman parte. De manera más contundente, en el documento de la ONU "Declaración de las naciones unidas sobre los derechos de los pueblos indígenas. Preguntas y respuestas", se plantea explícitamente que el reconocimiento de los pueblos indígenas y de la autodeterminación no lleva a crear otro Estado. La pregunta planteada es “¿El derecho a la autodeterminación sugiere la secesión de los pueblos indígenas en relación a los Estados soberanos?" y la respuesta enfática es: "No. El Artículo 5 de la Declaración aclara que el propósito del derecho a la autodeterminación reside en la participación de los pueblos indígenas en la vida nacional del Estado, al mismo tiempo que se protege la identidad cultural indígena" (ONU, 2007, p. 1). Así las cosas, se da un reconocimiento a la libre determinación de los pueblos indígenas en un Estado.

Aunque el hecho de que la ONU haya aprobado dicha Declaración constituye un avance importante en la política de reconocimiento de la autonomía indígena, las declaraciones ${ }^{6}$ en sí, no constituye una obligatoriedad en el cumplimiento por parte de los estados miembros, ellos deciden si la ratifican en sus legislaciones o no. En primera instancia, el único país de América que no votó a favor de la Declaración fue Colombia 7 , que se abstuvo de votar bajo el argumento que el Estado colombiano ha ratificado el Convenio 169 de la OIT que exige la consulta a los pueblos indígenas en asuntos que los afecten, la cual es contemplada por las leyes colombianas. Por tanto, -según dichos argumentos- sería contra el Convenio aceptar lo que la Declaración ahora refiere, que no es solamente la consulta, sino el consentimiento previo, libre e informado de los pueblos indígenas para cualquier actuación por parte de los gobiernos o de los Estados en general

6 Las Declaraciones que emite la ONU no son de carácter obligatorio para sus estados miembros. Estos deben ratificarla para que se convierta en Ley en el país, si no lo hacen no están obligados. Es decir, la Declaración no es un instrumento coercitivo del derecho internacional. Diferente a la Convención que es de obligatorio cumplimiento por parte de los Estados.

7 Bartolomé Clavero, miembro del Foro Permanente para las Cuestiones Indígenas, denunció que Colombia es el único país de América que se abstuvo de votar la Declaración de las Naciones Unidas sobre los Derechos de los Pueblos Indígenas con el argumento de que determinados artículos de la Declaración van en contra de la Constitución Política de Colombia. Pero precisamente, el derecho internacional ha surgido y se ha desarrollado debido a que existen Estados que no garantizan debidamente los derechos fundamentales del ser humano y el derecho internacional define un estándar de dichos derechos. En consecuencia, si las normas de un Estado no cumplen esos estándares, son las leyes o la Constitución las que tienen que adecuarse a dichos estándares expresó Clavero: "Nosotros no conocemos una constitución contra derechos Humanos universalmente declarados por la Asamblea general de Naciones Unidas". 
que pueda afectar sus derechos ${ }^{8}$. Este argumento que esgrimió Colombia para no votar positivamente la Declaración, le confirió el deshonroso papel de ser el único país de América en no avalarla, aunque años después se adhiriera. Fue sólo hasta el 24 de abril de 2009 que desde la Oficina del Alto Comisionado de la ONU para los Refugiados (Acnur) se afirma que Colombia se adhiere a la Declaración de los Derechos de los Pueblos Indígenas, importante decisión en la medida que el país posee un 3,4\% de indígenas (aproximadamente un millón), según del Departamento Administrativo de Nacional de Estadísticas -Dane- y más de noventa grupos étnicos. Comunidades que están sufriendo procesos de exterminio ${ }^{9}$ físico y cultural y por ende se les viola los derechos consagrados en la Declaración de los derechos de los pueblos indígenas.

El desconocimiento a las comunidades indígenas, la reconfiguración de los estados, la discriminación, el exterminio, los intereses internacionales han llevado a reclamos por parte de las comunidades y organizaciones indígenas, reclamos que tienen más de treinta años, en los cuales se ha visibilizado que los estados se quedaron chicos frente a la composición cultural que los conforma y frente a las legislaciones internacionales que de algún modo cobijan a las comunidades.

Para hacer frente a este proceso, la mayoría de estados en América Latina en la década del noventa, y sobre todo en el presente siglo, han realizado cambios constitucionales ya sea que hayan adoptado una nueva constitución o hecho enmiendas a las ya legisladas. Esto, a su vez, deja ver tanto la presión de los movimientos indígenas, que desde la década del noventa se ven resurgir y reclamar estados pluriétnicos y pluriculturales como la asimilación por parte de los estados de la política multicultural, que no afecta la estructura liberal sobre la cual basan su organización. Entre las

8 http://www.servindi.org/actualidad/3934

9 El primer semestre de 2009, en el departamento del Cauca, ha estado marcado por los asesinatos, las amenazas, los atentados, las detenciones arbitrarias y demás expresiones del escalonamiento del conflicto armado, lo cual viene generando desplazamiento y temor en la población e incremento de la desconfianza hacia las autoridades civiles y militares de la región por la falta de garantías a las comunidades, a las organizaciones sociales y a sus líderes. http://www.cric-colombia.org/inicio.htm constituciones latinoamericanas que proponen un estado multicultural y plural, se encuentra el caso de Colombia, que realiza la Constitución en 1991; Argentina en 1994; Nicaragua en 1995; Panamá en 1994; Guatemala en 1996; Perú en 1993; Ecuador en 2008; Bolivia en 2009 y México, que hizo una enmienda en 1992. Se hace un reconocimiento legal, pero en la conformación misma de los estados sigue fluyendo la idea de un Estado sólido, al decir de García (2004, p. 117), se sigue pensando en "términos de nación imagina desde los dispositivos estatales construidos históricamente".

Para abordar esta tensión entre las legislaciones internacionales, nacionales y las poblaciones indígenas, Olivé, en 2004, planteó la creación de los "derechos de los grupos" en los que cabrían los derechos indígenas. Aunque la nominación del derecho de los grupos haya sido rebasada por la nominación Pueblo, que fue reconocida en la Declaración de los derecho de los pueblos indígenas 10 en 2007, -propuesta que subyace a la nominación planteada por Olivé- es interesante porque trata de articular la autonomía indígena, los derechos individuales y los derechos colectivos desde una propuesta de reconocimiento a las comunidades indígenas en un Estado.

Siguiendo a Olivé (2004), el reconocimiento del derecho del grupo implica obligaciones al Estado y a los individuos del grupo: al Estado porque debe proveer al grupo, por ejemplo las escuelas para impartir la lengua, y al grupo porque se obliga a los padres a enviar a sus hijos a dicha escuela. Pueda que se otorgue cierta prioridad al grupo por encima del individuo, ya que pueden existir intereses colectivos cuya satisfacción exija constreñir

10 El concepto de indígenas sólo aparece en la legislación internacional en la década del ochenta con el Convenio 169 de la 0IT de 1988, antes de éste, la discusión de lo indígena se encontraba subsumida bajo el concepto genérico de "minorías étnicas". Se consideraba a los indígenas minoría por no constituir la mayor parte de un Estado, pero como lo afirma Bengoa (2000) existen dos Estados en el que predomina la población indígena (Guatemala y Bolivia), a pesar de ello se siguieron considerando minoría con el calificativo de étnico porque ello hacia una diferencia cultural frente a las otras minorías raciales, religiosas, lingüísticas entre otras. Sin embargo, el concepto de minoría no es adecuado para los pueblos indígenas porque allí entrarían infinidad de situaciones y grupos sociales, mientras que para los grupos indígenas es fundamental el reconocimiento de su origen territorial, situación de la que carecen las otras minorías. Por ello, resulta fundamental su reconocimiento como pueblo indígena, más no como minoría étnica. 
intereses individuales. Sin embargo, los intereses de grupo están estrechamente ligados con los intereses de los individuos y deben implicar restricciones sólo en los derechos no fundamentales de los individuos. En tal sentido, sería moralmente inaceptable cualquier derecho del grupo que viole los derechos humanos fundamentales, pero es moralmente aceptable el derecho a la diferencia aplicado a los miembros de un pueblo; de ahí se deriva al derecho del pueblo a la autodeterminación. La autonomía de un pueblo indígena sería un derecho del grupo análogo al derecho de la universalidad a ser autónomo.

Si pensamos cambiar el concepto de grupo por el de pueblo, podríamos decir con Olivé que el derecho de los pueblos no podría tener existencia sin el derecho a la autonomía. Por ello, es importante la autonomía política, entendida como la posibilidad de un grupo o institución que tiene el derecho de dictar sus propias normas en un ámbito de competencia, es decir de poder autogobernarse. Un pueblo sólo puede ser autónomo, si goza al menos de cierto grado de autonomía política. En la autonomía política, los pueblos deben también contar con procedimientos para adoptar reglas y normas que rigen su vida colectiva y para tomar decisiones colectivas. Los procedimientos deben ser resultado de la acción colectiva y permitir que las revisiones que hacen los individuos tengan consecuencias en la colectividad. La autonomía política requiere la autonomía de la comunidad en el sentido de autogobierno y autodeterminación.

La propuesta de Olivé, aunque resulta interesante, desconoce la voz de los pueblos indígenas al tratar de vincular la idea de derechos de los grupos con el ideal liberal de individuo, aspecto categóricamente rechazado por las comunidades para quienes el derecho colectivo prima. Sin embargo, son importantes los avances que han logrado en la materia de reconocimiento de los derechos de los pueblos indígenas, aunque la situación en que viven las comunidades muestra que estos derechos continúan siendo vulnerados.

\section{Reclamos de los pueblos indígenas}

Las naciones en América Latina se constituyeron bajo el ideal liberal de nación y modernidad, el cual que negaba la diversidad cultural de la que se compone el continente. El concepto de nación implicó asumir la idea de igualdad y libertad que subyace al concepto venido de Europa en el cual todos somos iguales y que no hay derecho a la diferencia. Por ejemplo, en la constitución ecuatoriana de finales de siglo XIX se declara: "La Nación ecuatoriana se compone de todos los ecuatorianos reunidos bajo el imperio de unas mismas leyes" a todos se cobija bajo los mismos preceptos, bajo el principio de igual de derechos y deberes, desde una ideal universal de homogeneidad y ciudadanía.

Los estados latinoamericanos se formaron como estados mononacionales, monolingues, un solo Estado, una sola nación, bajo la premisa de la homogeneidad cultural, es decir, todas las culturas que estaban en las fronteras establecidas debieron integrarse bajo el ideal blanco mestizo, que primaba para quienes dirigían el Estado. La homogeneización cultural contribuiría al ideario de nacionalidad, ideario fundamental para la consolidación de la nación, por ello, la historia del siglo XX muestra diferentes políticas indigenistas ${ }^{11}$ tendientes a integrar al indígena al patrón cultural, desconociendo sus características identitarias.

Este desconocimiento del indígena en las naciones de América Latina generó descontento, y los reclamos sobre la identidad cultural y el derecho a la diferencia no se hicieron esperar. La década del ochenta llegó con nuevos aires para el movimiento indígena, algunos se manifestaron antes, otros después, pero esta década marca un momento de afluencia de los reclamos identitarios y la organización de las comunidades indígenas lideradas por indígenas y con reivindicaciones culturales. Se exigía a los estados el reconocimiento de la pluriculturalidad, y en algunos casos la plurinacionalidad, estados más incluyentes de la diferencia en

11 La integración tiene como soporte importante la corriente teórica indigenista que estuvo estructurada bajo ideales de académicos reconocidos en diferentes países, y que ven en la integración y en el "desarrollo" del indio la posibilidad que el indio se supere, que salga del atraso en el que ha estado por siglos, es decir, deje de ser indio. La política indigenista representa un aspecto importante en América Latina tanto por la idea de modernidad que lleva implícita como por la del ideario de nación. Para Favre "la política indigenista constituye un capítulo en una política más general de modernización de la sociedad. Pero también representa un medio por medio del cual el Estado, cuya misión se precisa distinta y cuyo campo de intervención se amplía considerablemente, pretende convertir a esta sociedad en nación" (Favre, 1998, pp. 92-93). 
los cuales los indígenas tuvieran derecho al territorio, a la identidad, a la autonomía, la educación bilingüe, etc.

Por ejemplo, en México en 1971, por medio de la Ley de Reforma Agraria, se otorga validez legal a los documentos coloniales que amparaban la propiedad comunal de tierras y bosques para comunidades indígenas. Este acontecimiento posibilitó a las comunidades reclamar sus tierras, que habían sido usurpadas desde siglos atrás. Con el acontecimiento de la reforma agraria, se comienzan a organizar una serie de eventos en los que participan las nuevas organizaciones indígenas que buscan el reconocimiento en las políticas de Estado, reivindicando su derecho al idioma y a la cultura indígena y criticando las políticas indigenistas de integración. Los movimientos indígenas dejaban ver en sus discursos que no querían la integración, por el contrario, contemplaban otras opciones tendientes a considerar la pluralidad cultural del Estado. Desde esta perspectiva, se realiza en Pátzcuaro (México) el Primer Congreso Nacional de Pueblos Indígenas en 1975 al cual asisten diferentes comunidades indígenas. Allí, se percibe la diferencia de miradas entre los oficialistas (políticos indigenistas del Estado) y las nuevas organizaciones autónomas, que luchaban por mayor capacidad de negociación con el Estado.

Otras experiencias de organización indígena que presentan críticas a los estados mononacionales por sus miradas homogeneizantes son los quichuas del Ecuador. A mediados de la década del setenta, en el Cantón de Otavalo (provincia de Imbabura), surge un movimiento cultural de danza, música y teatro liderado por estudiantes que reivindican su identidad y los derechos económicos, sociales y culturales. Estos planteamientos interpelan los conceptos de Estado unitario, cultura nacional, folklore y campesinado que parecían ya haberse naturalizado en la sociedad e incluso en algunas organizaciones indígenas que se identificaban como campesinas. Por ello, una de las reivindicaciones de su identidad se hacía a partir del la lengua; los militantes de movimiento se comprometieron a utilizar el idioma en su vida cotidiana, en reuniones de trabajo y en la escritura: "En aquellos años se solía decir que la mejor manera de medir el nivel de compromiso de quienes decidimos que luchábamos por nuestros pueblos, era la seguridad y el orgullo con que utilizábamos el idioma materno" (Maldonado, 1997, p. 121). De manera similar ocurrió en Colombia con el Consejo Regional Indígena del Cauca -Cric-, fundado en 1971, que aglutina a las comunidades indígenas del suroriente del país. Dicha organización, desde su fundación, ha querido hacer evidente que en el país existen indígenas que tienen una identidad y una cultura distinta que no se reconocía por el Estado, aunque en el momento de su fundación varios dirigentes indígenas fueron asesinados.

Las manifestaciones regionales de los movimientos indígenas fueron la clave para que en la década del ochenta salieran a la esfera pública otras organizaciones reclamando sus derechos a la identidad y la cultura. En 1982, se fundó la Onic (Organización Nacional Indígena de Colombia), para el caso de Colombia, y en 1986 la Conaie (Confederación de Nacionalidades Indígenas del Ecuador), organizaciones que recogen el sentir de las comunidades indígenas en su país. En ambos casos, surgen de las propuestas de organizaciones regionales, que plantean la necesidad de la existencia de una organización nacional indígena que contribuya a su reconocimiento, que viabilice sus propuestas y recoja el sentir de las diferentes comunidades.

Estas organizaciones constituyen una articulación importante y cumplen un papel protagónico en los reclamos sociales y culturales que realizan las comunidades. En 1992, año en que se cumplían los 500 años de la invasión de Europa a América, las organizaciones lideraron manifestaciones en sus países y en general los movimientos indígenas del continente se organizaron para hacer evidente que ellos todavía estaban vivos, que formaban parte del continente, que no se trataba de una celebración, sino de una exigencia ante el mundo por su reconocimiento, y exigían resarcimiento de los atropellos a que habían sido sometidos durante esos siglos. Por ello, diferentes organizaciones indígenas del continente se manifestaron el 12 de octubre de 1992.

La emergencia de diferentes movimientos indígenas en América Latina ha afectado la noción de lo nacional y la homogeneidad cultural, haciéndose evidentes y participando de la vida nacional. 
Diferentes países fueron testigos de la irrupción de movimientos indígenas que exigían, entre otras cosas, el reconocimiento de la pluralidad cultural en sus Estados. Ejemplo de ello es el Movimiento Zapatista de Chiapas, México; los aymara y quichua en Bolivia; los mapuches en Chile, las diferentes etnias en Ecuador (quichuas y shuar), los nasa en Colombia; los cuna en Panamá, entre otros, que en la década del noventa hicieron su aparición en la esfera publica para evidenciar su existencia en los estados-nación homogéneos. Incluso, varios de estos movimientos han configurado poderes políticos importantes en sus países, llegando a los cargos más importantes, como el caso de Evo Morales en Bolivia.

Los reclamos indígenas se pueden leer como un conflicto étnico y como dice Giménez (2000, p. 67): "En la Medida en que las comunidades buscan "reconocimiento de la identidad minorizada, descalificada y estigmatizada en el proceso permanente de etnización perpetrado por los grupos dominantes y el Estado", aquí ellos no solamente exigen sus derechos, sino exigen su reconocimiento como cultura, reconocimiento a la identidad y a la diferencia, pues -como discutíamos en el apartado de identidad- el territorio que se convierte en una de las mayores reivindicaciones de los movimientos indígenas, es una parte fundamental y constitutiva de la identidad indígena. Las reivindicaciones identitarias que se observan en muchos estados contemporáneos:

Pueden interpretarse como una consecuencia de la centralización y burocratización del poder. Todo el esfuerzo de los grupos minoritarios se orienta, no tanto a reapropiarse de una identidad que frecuentemente es la que les ha sido otorgada por el dominante, sino poseer los medios para definirla por sí mismos y según sus propios criterios (Giménez, 2000, p. 56).

En el proceso de visibilización de las comunidades indígenas, pero a su vez de los reclamos a sus estados respecto a territorio, autonomía, educación, infraestructura, entre otros, los movimientos indígenas han utilizado múltiples estrategias tanto acciones de hecho como querellas judiciales. García Linera (2004), refiriéndose a Bolivia, plantea que existen múltiples formas en las acciones colectivas de los movimientos indígenas, él las llama "estructuras de movilización," entre ellas se encuentran las marchas, bloqueos a carreteras, concentraciones, bloqueos a acceso de áreas especificas (petroleras) y las acciones legales, como trámites judiciales ${ }^{12}$. Una de las estrategias que han usado los pueblos indígenas es exigir sus derechos a partir de las legislaciones políticas que se consagran en las respectivas constituciones nacionales, o desde instancias que abordan políticas culturales como la ONU, organismo internacional que avala la carta internacional de los derechos de los pueblos indígenas. Incluso se han hecho participes de las discusiones que se han dado en el seno de la ONU en torno a los Derechos de los Pueblos Indígenas ${ }^{13}$.

A su vez, estas estrategias se combinan con acciones que los visibilizan a nivel regional, nacional e incluso internacional, es el caso de las marchas multitudinarias que realizan los indígenas por sus países, recorriendo cientos de kilómetros, demorándose varias semanas hasta llegar a las ciudades principales, donde casi siempre se concentra el gobierno central para hacer evidentes sus inconformidades. Este tipo de manifestaciones multitudinarias se han realizado en varios países de América Latina; en Bolivia, en 2006, se realizó una marcha en el oriente del país reclamando el derecho al territorio, denominada la Gran Marcha; en Colombia, organizaciones indígenas del sur del país se movilizaron en 2008, reclamando al Estado por el territorio en sus resguardos; en Ecuador

12 Por ejemplo, la coordinadora de los Pueblos Étnicos de Santa Cruz -CPESC- en Bolivia para exigir territorio realiza "trámites judiciales de petición y seguimiento de demandas de tierras comunitarias de origen para preservar y garantizar la territorialidad de los pueblos. Se trata de una actividad que no sólo involucra a abogados y asesores de la organización, sino al sistema de conocimientos y consenso de los pueblos que han asumido esta lucha como elemento central, de sus expectativas, esfuerzos y recursos" (Garcia.2004). Esta estrategia se combina con otras acciones, pero es la base legal que les permite a las comunidades exigir al Estado democrático que cumpla con sus propias legislaciones.

13 En general la ONU está integrada por los Estados y organismos intergubernamentales, en tal sentido, las comunidades indígenas no tienen cabida, por ello cuando en 1995 se reunió el grupo encargado de analizar la Declaración sobre el derecho de los pueblos indígenas no habían participando en dicha comisión para los indígenas, por lo que fue necesaria, a petición de las comunidades, obtener una resolución para la participación de los pueblos indígenas, siendo la primera vez en la historia de la ONU donde ellos estarían aunque sin voto. 
se realizó una marcha en 1990 bajo las consignas "ni una hacienda para el año 1992", "la tierra será nuestra con ley o sin la ley”, pero también marchas por los 500 años de invasión en 1992; en México se llevó a cabo la marcha zapatista de 2001 con la consigna: "si no hay solución, habrá revolución", entre otras, que han recorrido cientos de kilómetros en el continente.

La visibilización, producto de los reclamos de los movimientos indígenas en el continente, lleva a la apertura de la "frontera étnica"14, es decir, a hacer evidente que en el continente existían comunidades indígenas que habían sido desconocidas por las políticas de los estados homogeneizantes. Para la población citadina del Ecuador, según García (2004, pp. 108-109), las movilizaciones indígenas del noventa mostraron una población que era desconocida, pues tradicionalmente a los indígenas se les consideraba campesinos, y el hecho de reivindicarse como indígenas y que muchos de ellos salieran de la Sierra o la Amazonía con toda su carga cultural y se desplazaran a la ciudades fue la prueba de su existencia y de que el Ecuador estaba constituido también por población indígena.

Las movilizaciones llevan a la visibilización del indígena, los indígenas salen a la luz pública como actores, sujetos históricos y líderes políticos,

14 El concepto de frontera étnica es acuñado por Guerrero (2000), quien al referirse al caso ecuatoriano plantea que en el Ecuador existió la frontera étnica que es una especie de barrera entre los blancos-mestizos e indígenas desde mediados del siglo XIX. Esta frontera se creó por medio de las concesiones que el Estado le otorgó a poderes patriarcales quienes generaron un proceso de dominación e invisibilización de las comunidades indígenas dejándolas por fuera de la vida pública. Para Guerrero, fue sólo hasta la emergencia de los movimientos indígenas de 1990 cuando esta frontera se comienza a fracturar.

\section{Bibliografía}

Bengoa, J. (2000). La emergencia indígena en América latina. Santiago de Chile: Fondo de Cultura Económica.

Favre, H. (1998). El indigenismo. México: Fondo de Cultura Económica.

García, F. (2004). La imaginación de lo nacional en tiempos de dolarización y crisis: nuevas estrategias pero, a su vez, este hecho de visibilización expresa la crítica a los Estados nacionales, se reivindica el derecho a la identidad, a la cultura de la diferencia en el Estado. Se podría afirmar que los levantamientos indígenas de la década del noventa, -aquellos referidos a los 500 años de invasión- y otros que reivindican la cultura indígena, su territorio, su autonomía, sus creencias y su educación dieron apertura a la frontera étnica, pues se evidenció que los estados no estaban constituidos por la homogeneidad y, por el contrario, se hizo evidente que los indígenas participarían públicamente en la configuración de nuevas relaciones de Estado que ellos representaban una importante diferencia en la concepción de Estado. En algunos países se les comienza a reconocer como sujetos políticos y actores importantes en la vida pública de los estados, esto se evidencia en Ecuador, Bolivia y México.

Todas las cuestiones anteriores muestran diferentes maneras en las que se ha venido pensando las comunidades indígenas en la era de la globalización. Sin embargo, son cuestiones irresueltas si se piensa desde dichas comunidades porque desde las culturas hegemónicas la propuesta que se viabiliza en la actualidad es liberalismo democrático y multiculturalismo. Por ello, las manifestaciones indígenas, en medio de la sociedad globalizada y multicultural, representan el valor a la diferencia y dejan claro que a pesar de las políticas multiculturales, el reconocimiento a las culturas e identidades colectivas desde las políticas liberales, no soluciona los problemas estructurales, especialmente aquellos en los que la posibilidad de reconocer al otro desde su diferencia resquebraja al Estado y las políticas culturales de los organismos internacionales. II

de representación del movimiento indígena ecuatoriano. En A. Grimson (comp.), La cultura en las crisis latinoamericanas. Buenos Aires: Clacso.

Giménez, G. (2000). Identidades étnicas: estado de la cuestión. En L. Reina (coord.), Los retos de la etnicidad en los estados-nación del siglo XXI. México: Ciesas/INI/Miguel Ángel Porrúa. 
Giménez, G. (2007). Estudios sobre la cultura y las identidades sociales. México: Consejo Nacional para la Cultura y las Artes, Conaculta.

García Linera, A. (coord.). (2004). Sociología de los movimientos sociales en Bolivia. Estructura de movilización, repertorios culturales y acción política. Bolivia: Oxfam-Diayonia.

Guerrero, A. (2001). La frontera étnica en el espacio de la crítica. En Íconos. Ecuador: Flacso.

Organización de las Naciones Unidas. (2007). Declaración de las Naciones Unidas sobre los derechos de los pueblos indígenas. Preguntas y respuestas. $13 \mathrm{de}$ septiembre de 2007.
Olivé, L. (2004). Interculturalismo y justicia social. México: Paidós.

Stavenhagen, R. (2000). ¿Es posible una nación multicultural?" En L. Reina (coord.), Los retos de la etnicidad en los estados-nación del siglo XXI. México: Ciesas/ INI/Miguel Ángel Porrúa.

Stavenhagen. R. (2007). Un mundo en el que caben muchos mundos. El reto de la globalización. En D. Gutiérrez Martínez y H. Balslev Clausen, Revisitar la etnicidad. México: El Colegio de Sonora-El Colegio Mexiquense-Siglo XIX Editores. 